\title{
The Situation and Experience of Teacher Training for Clinical Teaching in Rizhao Region, China
}

\author{
Hong Zhang ${ }^{1,}$, Jing Leng ${ }^{1}$, Hui Yang ${ }^{2}$, Shujuan $\mathrm{Xu}^{1}$, Gangping $\mathrm{Wang}^{3}$ and \\ Peng Wang ${ }^{1}$ \\ ${ }^{1}$ Science and education division, Rizhao people's hospital affiliated Jining Medical University, \\ Rizhao 276826, China; \\ ${ }^{2}$ Clinical skills training center division, Rizhao people's hospital, Rizhao 276826, China; \\ ${ }^{3}$ Department of Pathology, Rizhao People's hospitaly, Rizhao 276826, China.
}

azhanghong722@163.com Keywords: Teaching hospital; Clinical teaching; Medical students; Teacher training; Peer
assessment.

\begin{abstract}
To understand the state of clinical teaching and improve the level, we choose the case of Rizhao City People's Hospital to investigate the clinical teaching quality, and analysis the problems existed in clinical teaching. This article explains and demonstrates how to cultivate high quality of clinical teaching faculty in the hospital in recent years of work experience, from the ideological education, cultivate mainstay, teaching system and incentive system such as system introduced from the aspects such as the establishment and implementation of the construction methods and experience of clinical teaching faculty. The study describes some of the important aspects to be considered during the bedside teaching by evaluating current practice in a teaching hospital setting. It shows the importance of ward-based bedside teaching practice particularly in teaching hospitals despite the decline in this form of teaching in the training of medical students and interns in particular as regards the teaching and reinforcing of history-taking and physical examination skills.
\end{abstract}

\section{Introduction}

Most of the higher medical colleges and universities teaching hospital, carries certain clinical teaching tasks, this skills in peer teaching, assessment, and feedback are increasingly documented internationally as required graduate attributes in medicine[1,2]. Yet these skills are rarely taught in medical schools. Bedside-based clinical teaching play an important role in clinical teaching. Bedside teaching is the only medical learning situation where history-taking, physical examination, empathy, and a caring attitude can all be learnt simultaneously and by example. All physicians, at some point in their career, are responsible for the education of their peers and junior colleagues[1]. Bedside-based clinical teaching brings together a learning triad of patients, students, and tutors and involves an interaction[2]. Bedside-based clinical teaching acts as an important practical approach for the medical students acquisition of knowledge and clinical skills that are difficult to teach through other methods, as well as procedural, physical examination and communication skills[3,4]. In order to teach clinical skills effectively, a teacher must involve patients in the educational process, and there is strong evidence that patients favor the method; additionally, they report a better understanding of their illnesses when they are active participants in bedside teaching sessions[1,4]. Although young doctor are expected to develop clinical and research skills in preparation for residency, it is becoming clear that a young doctor should also be expected to develop abilities as a teacher. In clinical teaching, the clinic teacher is able to model the interpersonal skills and humanistic aspects of patient care, which are essential to a strong doctor-patient relationship. Young doctor can play as teacher to train medical students in education, but most of them graduated from medical school without formal training in this area. When such a program does not exist, young doctor can gain experience in education through participation in peer teaching, course design, educational committees, and medical education scholarship. in doing so, they attain important skills in the development, implementation, and 
evaluation of educational programs. These skills will serve them in their capacity as medical educators as they advance in their careers and gain increasing teaching responsibility as residents, fellows, and attending physicians.

\section{Object and method}

\subsection{Object.}

To understand the state of clinical teaching and improve the level, we choose the case of Rizhao City People's Hospital to investigate the clinical teaching quality, and analysis the problems existed in clinical teaching and clinical teaching teachers. We selected 500 medical students to 200 clinicians in Rizhao people's hospital affiliated Jining Medical University from January 2013 to June 2015, to study the medical theory of knowledge, combined with the compliance of teaching attitude, teaching methods, theory and practice, improve the students' ability in clinical practice and effect of questionnaire entries, in order to improve the consciousness and behavior of the clinical teaching of clinical teachers in the population as a whole. The 200 clinical teachers were in 15 wards in our hospital in this study. The personnel structure was shown in Table 1 . There were 56 senior titles, 144 intermediate titles people, the ratio was 2.57:1. MS and PhD: Bachelor number ratio was 1.56. There were 121 people for clinical practice more than 5 years, and 79 people lack of 5 years, their ratio was 1.53:1. There were 143 people's teaching training frequency equal or more than 2 times / years, and 57 lack of 2 times/years, the ratio was 2.51:1.

Table 1 The personnel structure

\begin{tabular}{lc}
\hline \multicolumn{1}{c}{ Group } & Number \\
\hline Professional title & \\
$\quad$ Senior & 56 \\
$\quad$ Intermediate & 144 \\
Academic degree & \\
$\quad$ Master and Doctor & 78 \\
$\quad$ Bachelor & 122 \\
Clinical practice period & \\
$\geq 8$ years & 121 \\
$<8$ years & 79 \\
Clinical teaching & \\
$\quad \geq 5$ years & 108 \\
$<5$ years & 92 \\
Receive training frequency & \\
$\geq 2$ times / year & 143 \\
$<2$ times / year & 57 \\
\hline
\end{tabular}

\subsection{The Method.}

SPSS ver 17. 0 (SPSS Inc.: Chicago, IL, USA) statistical software was used to detect the data. The database was established according to the questionnaire results assignment 1 on behalf of teaching quality outstanding medical student satisfaction; teaching assignment 0 represents quality generally, medical students are not satisfied with, combined with the overall evaluation of the medical theory knowledge, compliance of teaching attitude, teaching method of clinical theory and practice, students' clinical practice ability raise were satisfactory to excellent, have a not satisfied is unqualified. Measurement data between groups was compared with $t$ test, while enumeration data with $\chi^{2}$ test. The $P$ value was considered to be significant if less than 0.05 .

\section{Results}

The results of teachers' medical theoretical knowledge, teaching attitude compliance and Combination of teaching method theory and clinical practice were shown in Table 2,3 and 4. Clinical 
teachers in clinical teaching quality overall score excellent 138 cases, accounted for $69.0 \%$, and the teaching attitude compliance score excellent rate is $78.50 \%(157 / 200)$. The theory of teaching methods and clinical practice with excellent rate was 71.5\% (143/200), the medical theory knowledge score the excellent and good rate for $86.37 \%$ (171/200). Single factor analysis, teaching attitude, compliance, and the teaching method of theory and practice combined with teaching were related with teachers' professional title, years of clinical work, teaching experience and teaching training frequency respectively, $P<0.05$. And the results were independent of the degree of teacher education $(P>0.05)$. The knowledge of medical theory precisely the opposite. Medical theoretical knowledge was related with the teachers' degree $(P<0.05)$, and there was no correlation with the teacher's title, clinical work experience and the years of teaching and training frequency $(P>0.05)$.

Table 2 Survey results of teachers' medical theoretical knowledge

\begin{tabular}{|c|c|c|c|c|c|}
\hline Group & No. & 0 & 1 & $\chi^{2}$ & $P$ \\
\hline \multicolumn{6}{|l|}{ Professional title } \\
\hline Senior & 56 & 11 & 45 & \multirow{2}{*}{1.659} & \multirow{2}{*}{$>0.05$} \\
\hline Intermediate & 144 & 18 & 126 & & \\
\hline \multicolumn{6}{|l|}{ Academic degree } \\
\hline Master and Doctor & 78 & 6 & 72 & \multirow{2}{*}{4.780} & \multirow{2}{*}{$<0.05$} \\
\hline Bachelor & 122 & 23 & 99 & & \\
\hline \multicolumn{6}{|l|}{ Clinical practice period } \\
\hline$\geq 8$ years & 121 & 12 & 109 & \multirow{2}{*}{3.117} & \multirow{2}{*}{$>0.05$} \\
\hline$<8$ years & 79 & 7 & 72 & & \\
\hline \multicolumn{6}{|l|}{ Clinical teaching } \\
\hline$\geq 5$ years & 108 & 14 & 94 & \multirow{2}{*}{0.447} & \multirow{2}{*}{$>0.05$} \\
\hline$<5$ years & 92 & 15 & 77 & & \\
\hline \multicolumn{6}{|l|}{ Receive training frequency } \\
\hline$\geq 2$ times / year & 143 & 21 & 122 & \multirow{2}{*}{1.390} & \multirow{2}{*}{$>0.05$} \\
\hline$<2$ times / year & 57 & 8 & 49 & & \\
\hline
\end{tabular}

Note: Assignment 1 on behalf of the teaching quality is excellent, medical students satisfaction; assignment 0 on behalf of the general, not satisfied.

Table 3 Survey results of teachers' teaching attitude compliance

\begin{tabular}{|c|c|c|c|c|c|}
\hline Group & No. & 0 & 1 & $\chi^{2}$ & $P$ \\
\hline \multicolumn{6}{|l|}{ Professional title } \\
\hline Senior & 56 & 6 & 50 & \multirow{2}{*}{5.361} & \multirow{2}{*}{$<0.05$} \\
\hline Intermediate & 144 & 37 & 107 & & \\
\hline \multicolumn{6}{|l|}{ Academic degree } \\
\hline Master and Doctor & 78 & 19 & 59 & \multirow{2}{*}{0.373} & \multirow{2}{*}{$>0.05$} \\
\hline Bachelor & 122 & 24 & 98 & & \\
\hline \multicolumn{6}{|l|}{ Clinical practice period } \\
\hline$\geq 8$ years & 121 & 20 & 101 & \multirow{2}{*}{3.771} & \multirow{2}{*}{$<0.05$} \\
\hline$<8$ years & 79 & 23 & 56 & & \\
\hline \multicolumn{6}{|l|}{ Clinical teaching } \\
\hline$\geq 5$ years & 108 & 17 & 91 & \multirow{2}{*}{3.902} & \multirow{2}{*}{$<0.05$} \\
\hline$<5$ years & 92 & 26 & 66 & & \\
\hline \multicolumn{6}{|l|}{ Receive training frequency } \\
\hline$\geq 2$ times / year & 143 & 25 & 118 & \multirow{2}{*}{3.999} & \multirow{2}{*}{$<0.05$} \\
\hline$<2$ times / year & 57 & 18 & 39 & & \\
\hline
\end{tabular}

Note: Assignment 1 on behalf of the teaching quality is excellent, medical students satisfaction; assignment 0 on behalf of the general, not satisfied. 
Table 4 Survey results of teachers' teaching method

\begin{tabular}{|c|c|c|c|c|c|}
\hline Group & No. & 0 & 1 & $\chi^{2}$ & $P$ \\
\hline \multicolumn{6}{|l|}{ Professional title } \\
\hline Senior & 56 & 8 & 48 & \multirow{2}{*}{6.773} & \multirow{2}{*}{$<0.05$} \\
\hline Intermediate & 144 & 49 & 95 & & \\
\hline \multicolumn{6}{|l|}{ Academic degree } \\
\hline Master and Doctor & 78 & 24 & 54 & \multirow{2}{*}{0.167} & \multirow{2}{*}{$>0.05$} \\
\hline Bachelor & 122 & 33 & 89 & & \\
\hline \multicolumn{6}{|l|}{ Clinical practice period } \\
\hline$\geq 8$ years & 121 & 26 & 95 & \multirow{2}{*}{6.547} & \multirow{2}{*}{$<0.05$} \\
\hline$<8$ years & 79 & 31 & 48 & & \\
\hline \multicolumn{6}{|l|}{ Clinical teaching } \\
\hline$\geq 5$ years & 108 & 21 & 87 & \multirow{2}{*}{8.507} & \multirow{2}{*}{$<0.05$} \\
\hline$<5$ years & 92 & 36 & 56 & & \\
\hline \multicolumn{6}{|l|}{ Receive training frequency } \\
\hline$\geq 2$ times / year & 143 & 28 & 115 & \multirow{2}{*}{14.421} & \multirow{2}{*}{$<0.01$} \\
\hline$<2$ times / year & 57 & 27 & 30 & & \\
\hline
\end{tabular}

Note: Assignment 1 on behalf of the teaching quality is excellent, medical students satisfaction; assignment 0 on behalf of the general, not satisfied.

The results of overall evaluation were shown in Table 5. Overall evaluation, the quality of clinical teachers' clinical teaching were related to the professional title, clinical work experience, teaching time and frequency of teaching and training $(P<0.05)$, which has nothing to do with the teacher's degree $(P>0.05)$.

Table 5 Survey results of overall evaluation

\begin{tabular}{|c|c|c|c|c|c|}
\hline Group & No. & 0 & 1 & $\chi^{2}$ & $P$ \\
\hline Professional title & & 11 & 45 & \multirow{3}{*}{3.982} & \multirow{3}{*}{$<0.05$} \\
\hline Senior & 56 & 51 & 93 & & \\
\hline Intermediate & 144 & & & & \\
\hline Academic degree & & 28 & 50 & \multirow{3}{*}{1.083} & \multirow{3}{*}{$>0.05$} \\
\hline Master and Doctor & 78 & 34 & 88 & & \\
\hline Bachelor & 122 & & & & \\
\hline Clinical practice period & & 30 & 91 & & \\
\hline$\geq 8$ years & 121 & 32 & 47 & \multirow{2}{*}{4.807} & \multirow{2}{*}{$<0.05$} \\
\hline$<8$ years & 79 & & & & \\
\hline Clinical teaching & & 26 & 82 & & \\
\hline$\geq 5$ years & 108 & 36 & 56 & \multirow{2}{*}{4.585} & \multirow{2}{*}{$<0.05$} \\
\hline$<5$ years & 92 & & & & \\
\hline Receive training frequency & & 36 & 107 & & \\
\hline$\geq 2$ times / year & 143 & 26 & 31 & \multirow{2}{*}{7.033} & \multirow{2}{*}{$<0.01$} \\
\hline$<2$ times / year & 57 & 11 & 45 & & \\
\hline
\end{tabular}

Note: Assignment 1 on behalf of the teaching quality is excellent, medical students satisfaction; assignment 0 on behalf of the general, not satisfied. The outstanding considered as the overall evaluation of 4 items all satisfied; there was one item not satisfied,we considered as not qualified.

\section{Problems and Countermeasures}

Clinical education that integrates substantial bedside teaching is an effective approach to satisfying the public need to train intelligent, skilled, and compassionate clinicians[1,3]. Collaborating with learners, developing faculty skills, including the patient, and promoting a supportive institutional culture can rectify a variety of barriers to bedside clinical teaching. In this survey of clinical teachers, light was shed on the practicalities of bedside teaching and clinical tutors' understanding of effective styles. Skills in peer teaching, assessment, and feedback are increasingly documented internationally as required graduate attributes in medicine. Yet these skills are rarely taught in medical schools. Due to historical reasons, the teaching system is not perfect in our hospital. Most of clinical medical staff's consciousness of teaching and teaching ability is uneven, some of them are good and some of them are bad. The teaching system is not standardized. Part of the young doctor and master of clinical teachers 
are good in medical theory, but they are lack of systematic training with the teaching, lack of teaching consciousness, inappropriate teaching methods. The importance of the bedside are considered as the premier location for clinical teaching. It was also seen as the most logical location for medical instructors to reinforce history-taking and physical examination skills, and enhance observational skills. The medical students can learn how to be gentle with students and house staff, better communicates with patients, and maintain appropriate ethics and professionalism with the patient by bedside clinical teaching. Although highly qualified doctors are good at clinical experience, but they lack of system master the update of diagnosis and treatment theory of disease in recent years especially the World Health Organization and the American Cancer Association. A very small number of clinical teachers believed that teaching is a burden. The obstacles to bedside clinical teaching reported here can be categorized as teacher-related, for example, teacher had not been appropriately trained in bedside teaching, or the teacher's discipline was mainly technology-oriented, climate-related such as busy, noisy, or poorly equipped, patient related factors such as patients not interested in participating, or other factors[3-5].

According to the results of the survey, we strengthen the proportion of high seniority physicians' teachers, strengthen the teaching training. In the clinical teaching, the master's and doctoral degrees teachers are strengthen. Young doctors had been trained on how to teach medical students. The program was delivered as a four-module face-to-face program, providing theoretical background, practical examples, and active participation in skills teaching, small group teaching, clinical teaching, and assessment and feedback[3,6]. The outcomes of the program included the ability to plan small group learning activities, understand the steps in teaching a skill, and understanding the steps in providing effective feedback[3]. Facilitation included interactive large group PowerPoint presentations, as well as two small group sessions[3,6]. In the recent survey of clinical teachers in 2016, a high percentage of consultants demonstrated enthusiasm during bedside clinical teaching. We pay attention to the combination of compliance training and theory and practice of education and teaching method of teachers with master Dr., strengthen teacher's theory of high qualification and senior professional titles. This was attributed to the training in teaching. They were also more familiar with learning outcomes and were in favor of bedside clinical teaching.

\section{Conclusion}

Most of the higher medical colleges and universities teaching hospital, carries certain clinical teaching tasks, this skill in peer teaching, assessment, and feedback are increasingly documented internationally as required graduate attributes in medicine. Cultivate high quality of clinical teaching faculty in hospital include the ideological education, cultivate mainstay, teaching system and incentive system such as system introduced from the aspects such as the establishment and implementation of the construction methods and experience of clinical teaching faculty. The study describes some of the important aspects to be considered during the bedside teaching by evaluating current practice in a teaching hospital setting. It shows the importance of ward-based bedside teaching practice particularly in teaching hospitals despite the decline in this form of teaching in the training of medical students and interns in particular as regards the teaching and reinforcing of history-taking and physical examination skills.

\section{References}

[1]. C. van Diggele , A. Burgess, and C. Mellis , "Teacher training program for medical students: improvements needed” Adv Med Educ Pract. vol.6, pp.265-270, April 2015.

[2]. S.A. Seibert and E. Bonham, "Preparing Dedicated Education Unit Staff Nurses for the Role of Clinical Teacher”, J Nurses Prof Dev. vol.32, pp: 205-211, Jul-Aug 2016.

[3]. A.shehab, “Clinical Teachers' Opinions about Bedside-based Clinical Teaching”, Sultan Qaboos Univ Med J. vol.13, pp.121-126, Feb 2013. 
[4]. School of Medicine, Ninewells Hospital and Medical School, Dundee, UK. April 2012.

[5]. C.M. Crumlish, , M.A. Yialamas, G.T. McMahon, "Quantification of bedside teaching by an academic hospitalist group”, J Hosp Med, vol.4, pp.304-307. May 2009.

[6]. K.N. Williams, S. Ramani, B. Fraser and J.D. Orlander, "Improving bedside teaching: Findings from a focus group study of learners”, Acad Med. vol. 83, pp.257-264. March 2008 